\title{
KARAKTERISTIK BAHASA JURNALISTIK DAN PENERAPANNYA PADA MEDIA CETAK
}

\author{
Aryusmar \\ Jurusan Sastra Inggris, Fakultas Humaniora, BINUS University \\ Jln. Kemanggisan Ilir III No. 45, Kemanggisan, Palmerah, Jakarta Barat 11480
}

\begin{abstract}
Journalistic language is one kind of language used by mass media and had different characteristic with literature, scientific or conventional language in general. In journalistic language, the journalists should write according to facts and should not include their opinion; but the writing should also include informative, persuasive, and understandable meanings as general, brief, and clear. Journalistic language is a language used in public media written by considering some characteristics in order to be easily understood by the reader in general. Therefore, this article is intended to explore those characteristics and their implementation. The result shows that there are six characteristics of Journalistic language namely: brief, dense, simple, straightforward, interesting and clear. It is also found that some printed media in Indonesia haven't met those characteristics yet.
\end{abstract}

Keywords: journalistic language, characteristics of journalistic language

\begin{abstract}
ABSTRAK
Bahasa jurnalistik adalah suatu jenis bahasa yang digunakan oleh media massa dan sangat berbeda karakteristiknya dengan bahasa sastra, bahasa ilmu atau bahasa baku pada umumnya. Dalam bahasa jurnalistik wartawan harus menulis sesuai fakta dan tidak boleh beropini, namun tulisan tersebut harus mengandung makna informatif, persuasif, dan yang bisa dipahami secara umum, singkat, jelas. Bahasa jurnalistik merupakan bahasa yang digunakan dalam media publik yang ditulis dengan beberapa karakteristik untuk bisa dipahami oleh pembaca secara umum. Tulisan ini menganalisis karakteristik media jurnalistik dan implementasinya. Dalam hasil analisis, terdapat 6 karakteristik bahasa jurnalistik: singkat, padat, sederhana, lugas, menarik, lancar dan jelas. Tetapi disimpulkan bahwa kebanyakan pemberitaan yang dimuat di media cetak di Indonesia dalam implementasinya belum memenuhi unsur-unsur yang menjadi karakteristik bahasa jurnalistik tersebut.
\end{abstract}

Kata kunci: bahasa jurnalistik, karakter bahasa jurnalistik 


\section{PENDAHULUAN}

Bahasa adalah nyawa dalam setiap media massa, baik media cetak maupun elektronika. Bahasa sebagai alat komunikasi yang efektif merupakan ekspresi penggunaannya sesuai dengan situasi kebahasaan yang menuntut. Atas dasar inilah, maka pepatah mengatakan, "Bahasa menunjukkan bangsa.” Artinya setiap media memiliki ragam bahasa yang berbeda-beda sesuai dengan khalayak yang ditujunya. Ragam bahasa ini pula yang menjadi identitas setiap media, yang dapat membedakan antara media yang satu dengan media yang lainnya. Oleh karena itu, setiap wartawan harus memiliki pengetahuan tentang bahasa jurnalistik yang baik dan benar. Media massa Indonesia pada umumnya menggunakan bahasa Indonesia sebagai bahasa jurnalistik.

Bahasa jurnalistik adalah laras atau ragam dalam bahasa Indonesia, seperti juga ada bahasa hukum atau bahasa niaga. Meskipun bahasa jurnalistik memiliki sejumlah kekhususan, namun bahasa jurnalistik adalah bahasa Indonesia yang baku, yang harus memperhatikan kaidah-kaidah yang berlaku. Jadi bahasa jurnalistik Indonesia tetap bahasa Indonesia yang baku, baik, dan benar. Pandangan yang sama juga dikemukakan Sudaryanto (1995) bahwa bahasa jurnalistik atau biasa disebut dengan bahasa pers, merupakan salah satu ragam bahasa kreatif bahasa Indonesia di samping terdapat juga ragam bahasa akademik (ilmiah), ragam bahasa usaha (bisnis), ragam bahasa filosofik, dan ragam bahasa literer (sastra).

Bahasa jurnalistik, berada di tengah antara bahasa ilmu dan bahasa sastra. Bahasa ilmu biasanya penuh fakta, kering dan tidak bergaya, sementara bahasa sastra biasanya imaginatif dan penuh gaya. Lain halnya dengan bahasa jurnalistik tetaplah harus berdasarkan pada fakta, tetapi harus ada gayanya. Bahasa jurnalistik ditulis dengan mempertimbangkan ruang dan waktu, karena itu unsur kehematan dan efektifitas sangat penting. Tidak mungkin wartawan menulis untuk media massa semaunya dengan tidak memperhitungkan ruangan dan waktu yang tersedia (deadline). Bahasa Jurnalistik juga perlu memepertimbangkan pasar (pembaca).

Meskipun bahasa jurnalistik memiliki sejumlah kekehususan, tetapi ia bahasa Indonesia yang baku, yang harus memperlihatkan kaidah-kaidah yang berlaku. Jadi bahasa jurnalistik tetap bahasa baku, baik dan benar. Bahasa jurnalistik merupakan bahasa komunikasi massa sebagai tampak dalam harian-harian surat kabar dan majalah. Dengan fungsi yang demikian itu bahasa jurnalistik itu harus jelas dan mudah dibaca dengan tingkat ukuran intelektual minimal.

penggunaan bahasa jurnalistik.

Penggunaan bahasa jurnalistik berbeda-beda berdasarkan jenis tulisan apa yang akan terberitakan. Suroso pada presentasinya di KIPBIPA IV mengemukakan bahwa bahasa jurnalistik yang digunakan untuk menuliskan reportase investigasi tentu lebih cermat bila dibandingkan dengan bahasa yang digunakan dalam penulisan features. Bahkan bahasa jurnalistik pun sekarang sudah memiliki kaidah-kaidah khas seperti dalam penulisan jurnalisme perdamaian (McGoldrick \& Lynch, 2000). Bahasa jurnalistik yang digunakan untuk menulis berita utama_ada yang menyebut laporan utama, forum utama--akan berbeda dengan bahasa jurnalistik yang digunakan untuk menulis tajuk dan features. Dalam menulis banyak faktor yang dapat mempengaruhi karakteristik bahasa jurnalistik karena penentuan masalah, angle tulisan, pembagian tulisan, dan sumber (bahan tulisan). Namun demikian sesungguhnya bahasa jurnalistik tidak meninggalkan kaidah yang dimiliki oleh ragam bahasa Indonesia baku dalam hal pemakaian kosakata, struktur sintaksis dan wacana (Reah, 2000). Karena berbagai keterbatasan yang dimiliki surat kabar (ruang, waktu) maka bahasa jurnalistik memiliki sifat yang khas yaitu singkat, padat, sederhana, lancar, jelas, lugas dan menarik. Kosakata yang digunakan dalam bahasa jurnalistik mengikuti perkembangan bahasa dalam masyarakat. 
Sifat-sifat tersebut merupakan hal yang harus dipenuhi oleh ragam bahasa jurnalistik mengingat surat kabar dibaca oleh semua lapisan masyarakat yang tidak sama tingkat pengetahuannya. Dengan kata lain bahasa jurnalistik dapat dipahami dalam ukuran intelektual minimal. Hal ini dikarenakan tidak setiap orang memiliki cukup waktu untuk membaca surat kabar. Oleh karena itu bahasa jurnalistik sangat mengutamakan kemampuan untuk menyampaikan semua informasi yang dibawa kepada pembaca secepatnya dengan mengutamakan daya komunikasinya.

\section{Karakteristik Bahasa Jurnalistik}

Sebagai salah satu ragam bahasa, bahasa jurnalistik memiliki sifat- sifat yang khas, Lukas (2006) dalam buku membangun kapasitas media yang diterbitkan Sekretariat Dewan Pers mengutip beberapa pendapat tentang bahasa jurnalistik antara lain: (1) Prof. S. Wojowasito, bahasa jurnalistik adalah bahasa komunikasi massa sebagai tampak dalam harian-harian dan majalah-majalah; (2) Rosihan Anwar, satu ragam bahasa yang digunakan wartawan yang memiliki sifat-sifat khas: singkat, padat, sederhana, lancar, jelas, lugas, dan menarik (Anwar, 1991); (3) M. Wonohito (bahasa surat kabar), suatu jenis bahasa tertulis yang lain sifat-sifatnya dengan bahasa sastra, bahasa ilmu atau bahasa buku pada umumnya; (4) Kurniawan Junaedhie (Ensiklopedia Pers Indonesia), bahasa yang digunakan oleh penerbitan pers. Bahasa yang mengandung makna informatif, persuasif, dan yang secara konsensus merupaan kata-kata yang bisa dimengerti secara umum, harus singkat tapi jelas dan tidak bertele-tele; (5) Moh. Ngafeman (Kamus Jurnalistik AZ), bahasa komunikasi massa dengan pilihan kosakata yang sederhana agar dapat dipahami oleh segenap lapisan masyarakat; (6) Adinegoro, tiap berita dan cerita harus padat karena itu disadjikan setjara mudah difahamkan, terang dan tidak sulit membatjanja sehingga orang jang membatjanja tidak usah berfikir pandjang untuk mengetahui apa jang diberitakan itu. Oleh sebab itu kita dapati dalam kalimat-kalimat ringkas, kata-kata yang tepat, dan ungkapan-ungkapan yang hidup.

Menurut Badudu (1988) bahasa jurnalistik memiliki sifat-sifat khas yaitu singkat, padat, sederhana, lugas, menarik, lancar dan jelas. Sifat-sifat itu harus dimiliki oleh bahasa pers, bahasa jurnalistik, mengingat surat kabar dibaca oleh semua lapisan masyarakat yang tidak sama tingkat pengetahuannya.

Dari beberapa pandangan di atas penulis sependapat dengan pandangan bahwa bahasa jurnalistik merupakan suatu bahasa komunikasi masa yang digunakan wartawan dalam penulisan produk pers yang memiliki karakteristik yaitu: singkat, padat, sederhana, lugas, menarik, jelas sehingga dapat dimengerti oleh masyarakat pembaca. Oleh karena itu, fokus makalah ini hanya dibatasi pada kajian tentang karakteristik bahasa jurnalistik bersifat singkat, padat, sederhana, lugas, menarik, jelas dan implementasinya pada media cetak Indonesia.

Lukas (2006) diperkuat Suroso (2001) pada KIPBIPA IV menjelaskan kriteria bahasa jurnalistik: (1) singkat, artinya bahasa jurnalistik harus menghindari penjelasan yang panjang dan bertele-tele; (2) padat, artinya bahasa jurnalistik yang singkat itu sudah mampu menyampaikan informasi yang lengkap. Semua yang diperlukan pembaca sudah tertampung didalamnya. Menerapkan prinsip 5W 1H, membuang kata-kata mubazir dan menerapkan ekonomi kata; (3) sederhana, artinya bahasa pers sedapat-dapatnya memilih kalimat tunggal dan sederhana, bukan kalimat majemuk yang panjang, rumit, dan kompleks. Kalimat yang efektif, praktis, sederhana pemakaian kalimatnya, tidak berlebihan pengungkapannya (bombastis); (4) lugas, artinya bahasa jurnalistik mampu menyampaikan pengertian atau makna informasi secara langsung dengan menghindari bahasa yang berbunga-bunga; (5) menarik, artinya dengan menggunakan pilihan kata yang masih hidup, tumbuh, dan berkembang. Menghindari kata-kata yang sudah mati; (6) jelas, artinya informasi yang disampaikan jurnalis dengan mudah dapat dipahami oleh khalayak umum (pembaca). Struktur kalimatnya tidak menimbulkan penyimpangan/pengertian makna yang berbeda, menghindari ungkapan bersayap atau bermakna ganda (ambigu). Oleh karena itu, seyogyanya bahasa jurnalistik menggunakan kata-kata yang bermakna 
denotatif. Namun seringkali kita masih menjumpai judul berita: Tim Ferrari Berhasil Mengatasi Rally Neraka Paris-Dakar. Jago Merah Melahap Mall Termewah di Kawasan Jakarta. Polisi Mengamankan Oknum Pemerkosa dari Penghakiman Massa.

\section{Implementasi Karakteristik Bahasa Jurnalistik Media Cetak Indonesia}

Implementasi karakteristik bahasa jurnalistik yang bersifat singkat, artinya bahasa jurnalistik harus menghindari penjelasan yang panjang dan bertele-tele. Contoh:

Blair tidak perlu mundur, ......... Angka-angka itu diperoleh dari jajak pendapat YouGovyang diadakan sehari setelah pemeriksaan hukum atas kematian David Kelly diistirahatkan selama 10 hari untuk memberikan kesempatan kepada hakim Lord hutton menentukan saksisaksi mata yang harus dipanggil untuk pemeriksaan silang yang memperlihatkan responden lebih menentang Blair daripada mendukungnya.

(Kompas, judul "Seruan pada Blair untuk Mundur makin Kuat")

Akan lebih baik jika dibuat dalam beberapa kalimat, misalnya:

Angka-angka itu diperoleh dari jajak pendapat YouGov, yang memperlihatkan responden lebih menentang Blair daripada mendukungnya. Jajak pendapat diadakan sehari setelah pemeriksaan hukum atas kematian David Kelly diistirahatkan 10 hari untuk memberikan kesempatan kepada Hakim Lord Hutton menentukan saksi-saksi mata untuk pemeriksaan silang.

Implementasi karakteristik bahasa jurnalistik yang bersifat padat, artinya bahasa Jurnalistik yang singkat itu harus mampu menyampaikan informasi yang lengkap. Semua yang diperlukan pembaca sudah tertampung di dalamnya dengan menerapkan prinsip $5 \mathrm{~W}$ (Who, What, Where, When, Why) + 1 H (How), membuang kata-kata mubazir dan menerapkan ekonomi kata. Contoh:

Gubernur Papua J.P. Salossa mengatakan,kasus kelaparan di kabupaten Yahukimo bukan kasus yang luar biasa. Menurut dia, kerawanan pangan di yahukimo sering terjadi karena sejumlah hal, diantaranya kendala alam, seperti kondisi yang tidak memungkinkan untuk menanam tanaman pangan.

(Koran Tempo 11 Desember 2005, hlm 1)

Implementasi karakteristik bahasa jurnalistik yang bersifat sederhana, artinya bahasa jurnalistik sedapat-dapatnya memilih kalimat tunggal dan sederhana, bukan kalimat majemuk yang panjang, rumit dan kompleks. Kalimat yang efektif, fraktis sederhana pemakaian kalimatnya, tidak berlebihan pengungkapannya (bombastis). Contoh:

Hadirnya UU system keolahragaan nasional membuat sebagian besar Kabid Organisasi KONI daerah dan PB/PP yang mengikuti rapat kerja sehari (24 September) bidang organisasi di KONI pusat yang dihadiri seperti lesu dasar menanggapi bahasan materi tentang penyempurnaan AD/ART KONI pusat, penyelenggaraan PON, serta Olympic Solidarity. (Kompas 7 Oktober 2005, hal. 42, “Jangan Malu Untuk Berkaca”)

Contoh berita di atas dapat dibuat lebih sederhana:

UU system keolahragaan nasional membuat lesu darah 32 Konida dan 30 pengurus induk organisasi yang haddir pada rapat kerj bidang organisasi KONI pusat 24 september, mereka tak berminat membahas penyempurnaan AD/ART KONI Pusat, penyelenggaraan PON, dan Olympic Solidarity... 
Implementasi karakteristik bahasa jurnalistik yang bersifat lugas, artinya bahasa jurnalistik mampu menyampaikan pengertian atau makna informasi secara langsung dengan menghindari bahasa yang berbunga-bunga. Contoh:

Kepala Kepolisian Republik Indonesia Jendral SUTANTO membantah berita bahwa jajarannya mengawasi gerak-gerik pesantren di Indonesia untuk menengah terorisme. Dengan wajah geram, sutanto mengungkapkan kekecewaannya karena merasa media terus mengekspos prihal rencana polisi yang ingin mengambil sidik jari santri sebagai bentuk pengawasan. "kami tidak pernah mengusulkannya," kata Sutanto...

(Koran Tempo, 12 Desember 2005, hlm. A5, “Kepala Polisi Membantah Awasai Pesantren”)

Implementasi karakteristik bahasa jurnalistik yang bersifat menarik, artinya bahasa jurnalistik harus menggunakan pilihan kata yang masih hidup, tumbuh, dan berkembang. Menghindari kata-kata yang sudah mati. Contoh:

Dering telepon seluler itu sejenak mengganggu konsentrasi Soekotjo Soeparto, anggota komisi Yudisial. Apalagi, di layar tak muncul nomor dan penelpon. "Saya Probosutedjo,” si penelpon memperkenalkan diri. "Saya dengar puitisan sudah keluar, saya tak menyangka begitu cepat.” Pembicarapun berlanjut. "Intinya, probo mengadu dan meminta komisi Yudisial mendukungnya," kata Soekotjo...

(Majalah Tempo, 11 Desember 2005, hlm 104)

Implementasi karakteristik bahasa jurnalistik yang bersifat jelas artinya bahasa jurnalistik harus menyampaikan informasi yang mudah dipahami oleh khalayak umum (pembaca). Struktur kalimatnya tidak menimbulkan penyimpangan/pengertian makna yang berbeda, menghindari ungkapan bersayap atau bermakna ganda (ambigu). Oleh karena itu, seyogianya bahasa jurnalistik menggunakan kata-kata yang bermakna denotatif. Contoh:

Ribuan petak sawah di beberapa Kabupaten Pacitan terendam air akibat hujan deras sekitar 10 jam. Hujan tersebut juga mengakibatkan tanggul sungai di tiga titik jebol, ratusan rumah penduduk tergenang air, dan beberap tempat longsor. Tidak ada korban jiwa dalam peristiwa ini. (Kompas 12 Desember 2005, hlm.15, "Ribuan Petak Sawah di Pacitan Terendam”)

Dalam mengimplementasikan ke-6 prinsip tersebut Suroso (2001) pada KIPBIPA IV memberikan pandangan bahwa dalam penerapannya tentunya diperlukan latihan berbahasa tulis yang terus-menerus, melakukan penyuntingan yang tidak pernah berhenti. Dengan berbagai upaya pelatihan dan penyuntingan, barangkali akan bisa diwujudkan keinginan jurnalis untuk menyajikan ragam bahasa jurnalistik yang memiliki rasa dan memuaskan dahaga selera pembacanya.

Dipandang dari fungsinya, bahasa jurnalistik merupakan perwujudan dua jenis bahasa yaitu seperti yang disebut Halliday (1972) sebagai fungsi ideasional dan fungsi tekstual atau fungsi referensial, yaitu wacana yang menyajikan fakta-fakta. Namun, persoalan muncul bagaimana cara mengkonstruksi bahasa jurnalistik itu agar dapat menggambarkan fakta yang sebenarnya. Persoalan ini oleh Leech (1993) disebut retorika tekstual yaitu kekhasan pemakai bahasa sebagai alat untuk mengkonstruksi teks. Dengan kata lain prinsip ini juga berlaku pada bahasa jurnalistik.

Terdapat empat prinsip retorika tekstual yang dikemukakan Leech (1993), yaitu prinsip prosesibilitas, prinsip kejelasan, prinsip ekonomi, dan prinsip ekspresivitas. Prinsip prosesibilitas, menganjurkan agar teks disajikan sedemikian rupa sehingga mudah bagi pembaca untuk memahami pesan pada waktunya. Dalam proses memahami pesan penulis harus menentukan: (a) bagaimana membagi pesan-pesan menjadi satuan; (b) bagaimana tingkat subordinasi dan seberapa pentingnya masing-masing satuan; dan (c) bagaimana mengurutkan satuan-satuan pesan itu. Ketiga macam itu harus saling berkaitan satu sama lain. 
Penyusunan bahasa jurnalistik dalam surat kabar berbahasa Indonesia, yang menjadi faktafakta harus cepat dipahami oleh pembaca dalam kondisi apa pun agar tidak melanggar prinsip prosesibilitas ini. Bahasa jurnalistik Indonesia disusun dengan struktur sintaksis yang penting mendahului struktur sintaksis yang tidak penting. Perhatikan contoh berikut:

(1) Pangdam VIII/Trikora Mayjen TNI Amir Sembiring mengeluarkan perintah tembak di tempat, bila masyarakat yang membawa senjata tajam, melawan serta tidak menuruti permintaan untuk menyerahkannya. Jadi petugas akan meminta dengan baik. Namun jika bersikeras dan melawan, terpaksa akan ditembak di tempat sesuai dengan prosedur (Kompas, 24/1/99)

(2) Ketua Umum PB NU KH Abdurahman Wahid (Gus Dur) mengadakan kunjungan kemanusiaan kepada Ketua Gerakan Perlawanan Timor (CNRT) Xanana Gusmao di LP Cipinang, Selasa (2/2) pukul 09.00 WIB. Gus Dur didampingi pengurus PBNU Rosi Munir dan staf Gus Dur, Sastro. Turut juga Aristides Kattopo dan Maria Pakpahan

(Suara Pembaruan, 2/2/99)

Contoh (1) terdiri dari dua kalimat, yaitu kalimat pertama menyatakan pesan penting dan kalimat kedua menerangkan pesan kalimat pertama. Contoh (2) terdiri dari tiga kalimat, yaitu kalimat pertama menyatakan pesan penting dan kalimat kedua serta kalimat ketiga menyatakan pesan yang menerangkan pesan kalimat pertama.

Prinsip kejelasan, yaitu agar teks itu mudah dipahami. Prinsip ini menganjurkan agar bahasa teks menghindari ketaksaan (ambiguity). Teks yang tidak mengandung ketaksaan akan dengan mudah dan cepat dipahami. Perhatikan contoh:

(3) Ketika mengendarai mobil dari rumah menuju kantornya di kawasan Sudirman, seorang pegawai bank, Deysi Dasuki, sempat tertegun mendengar berita radio. Radio swasta itu mengumumkan bahwa kawasan Semanggi sudah penuh dengan mahasiswa dan suasananya sangat mencekam (Republika, 24/11/98)

(4) Wahyudi menjelaskan, negara rugi karena pembajak buku tidak membayar pajak penjualan (PPN) dan pajak penghasilan (PPH). Juga pengarang, karena mereka tidak menerima royalti atas karya ciptaannya. (Media Indonesia, 20/4/1997).

Contoh (3) dan (4) tidak mengandung ketaksaan. Setiap pembaca akan menangkap pesan yang sama atas teks di atas. Hal ini disebabkan teks tersebut dikonstruksi oleh kata-kata yang mengandung kata harfiah, bukan kata-kata metaforis.

Prinsip ekonomi. Prinsip ekonomi menganjurkan agar teks itu singkat tanpa harus merusak dan mereduksi pesan. Teks yang singkat dengan mengandung pesan yang utuh akan menghemat waktu dan tenaga dalam memahaminya. Sebagaimana wacana dibatasi oleh ruang wacana jurnalistik dikonstruksi agar tidak melanggar prinsip ini. Untuk mengkonstruksi teks yang singkat, dalam wacana jurnalistik dikenal adanya cara-cara mereduksi konstituen sintaksis yaitu (i) singkatan; (ii) elipsis, dan (iii) pronominalisasi. Singkatan, baik abreviasi maupun akronim, sebagai cara mereduksi konstituen sintaktik banyak dijumpai dalam wacana jurnalistik.

(5) Setelah dipecat oleh DPR AS karena memberikan sumpah palsu dan menghalang-halangi peradilan, Presiden Bill Clinton telah menjadi presiden kedua sejak berdirinya Amerika untuk diperintahkan diadili di dalam senat (Suara Pembaruan, 21/12/98)

(6) Ketua DPP PPP Drs. Zarkasih Noer menyatakan, segala bentuk dan usaha untuk menghindari disintegrasi bangsa dari mana pun atau siapa pun perlu disambut baik (Suara Pembaruan, 21/12/98 
Pada contoh (5) terdapat abreviasi DPR AS. Pada contoh (6) terdapat abreviasi DPP PPP. Selain itu ada abreviasi lain seperti SARA, GPK, OTB, OT, AMD, SDM. AAK, GPK, dll. Terdapat pula berbagai bentuk akronim dengan variasi pembentukannya walaupun seringkali tidak berkaidah. Misalnya. curanmor, curas, miras, dan lain-lain.

Elipsis merupakan salah satu cara mereduksi konstituen sintaktik dengan melesapkan konstituen tertentu.

(7) AG XII Momentum gairahkan olahraga Indonesia (Suara Pembaruan, 21/12/98)

(8) Jauh sebelum Ratih diributkan, Letjen (Pur) Mashudi, mantan Gubernur Jawa Barat dan mantan Ketua Umum Kwartir Gerakan Pramuka telah menerapkan ide mobilisasi massa. Konsepnya memang berbeda dengan ratih (Republika, 223/12/98)

Pada contoh ((7) terdapat pelepasan afiks me(N) pada verba gairahkan. Pelepasan afiks seperti contoh (7) di atas sering terdapat pada judul wacana jurnalistik. Pada contoh (8) terdapat pelesapan kata mobilisasi masa pada kalimat kedua.

Pronominalisasi merupakan cara mereduksi teks dengan menggantikan konstituen yang telah disebut dengan pronomina. Pronomina Pengganti biasanya lebih pendek daripada konstituen terganti.

(9) Ketua Umum Dewan Pimpinan Pusat Partai Demokrasi Indonesia (DPP PDI) hasil kongres Medan Soerjadi dan Sekjen Buttu Hutapea pada hari Minggu (23/8) sekitar pukul 18.30 Wita tiba di bandara Mutiara, Palu Sulawesi Tengah, dengan diangkut pesawat khusus. Keduanya datang untuk mengikuti Kongres V PDI, dengan pengawalan ketat langsung menunggu Asrama Haji dan menginap di sana. (Kompas, 24/8/98)

(10) Hendro Subroto bukan militer. Sebagai seorang warga sipil, jejak pengalamannya dalam beragam mandala pertempuran merupakan rentetan panjang sarat pengalaman mendebarkan. Ia hadir ketika Kahar Muzakar tewas disergap pasukan Siliwangi di perbukitan Sulsel (Kompas, 24/8/98).

Pada contoh (9) tampak bahwa keduanya pada kalimat kedua merupakan pronominalisasi kalimat pertama. Pada contoh (10) kata Ia mempronominalisasikan Hendro Subroto, sebagai warga sipil pada kalimat pertama dan kedua.

Prinsip ekspresivitas.Prinsip ini dapat pula disebut prinsip ikonisitas. Prinsip ini menganjurkan agar teks dikonstruksi selaras dengan aspek-aspek pesan. Dalam wacana jurnalistik, pesan bersifat kausalitas dipaparkan menurut struktur pesannya, yaitu sebab dikemukakan terlebih dahulu baru dikemukakan akibatnya. Demikian pula bila ada peristiwa yang terjadi berturut-turut, maka peristiwa yang terjadi lebih dulu akan dipaparkan lebih dulu dan peristiwa yang terjadi kemudian dipaparkan kemudian.

(11) Dalam situasi bangsa yang sedang kritis dan berada di persimpangan jalan, karena adanya benturan ide maupun paham politik, diperlukan adanya dialog nasional. "Dialog diperlukan untuk mengubur masa lalu, dan untuk start ke masa depan”. Tutur Prof. Dr. Nurcholis Madjid kepada Kompas di kediamannya di Jakarta Rabu (23/12). (Kompas, 24/12/98).

Pada contoh (11) tampak bahwa kalimat pertama menyatakan sebab dan kalimat kedua mendatangkan akibat. 
Walaupun di dunia penerbitan telah ada buku-buku jurnalistik praktis karya Rosihan Anwar (1991), Asegaf (1982), Jacob Oetama (1987), Ashadi Siregar, dll, namun masih perlu dimunculkan petunjuk akademik maupun teknis pemakaian bahasa jurnalistik. Dengan mengetahui karakteristik bahasa pers Indonesia - termasuk sejauh mana mengetahui penyimpangan yang terjadi, kesalahan dan kelemahannya — maka akan dapat diformat pemakaian bahasa jurnalistik yang komunikatif.

Terdapat beberapa penyimpangan bahasa jurnalistik dibandingkan dengan kaidah bahasa Indonesia baku, di antaranya: penyimpangan morfologis, kesalahan sintaksis, kesalahan kosakata, kesalahan ejaan, dan kesalahan pemenggalan.

Peyimpangan morfologis, peyimpangan ini sering terjadi dijumpai pada judul berita surat kabar yang memakai kalimat aktif, yaitu pemakaian kata kerja tidak baku dengan penghilangan afiks. Afiks pada kata kerja yang berupa prefiks atau awalan dihilangkan. Kita sering menemukan judul berita misalnya: Polisi Tembak Mati Lima Perampok Nasabah Bank. Israil Tembak Pesawat Matamata. Amerika Bom Lagi Kota Bagdad.

Kesalahan sintaksis, kesalahan berupa pemakaian tatabahasa atau struktur kalimat yang kurang benar sehingga sering mengacaukan pengertian. Hal ini disebabkan logika yang kurang bagus. Contoh: Kerajinan Kasongan Banyak Diekspor Hasilnya ke Amerika Serikat. Seharusnya Judul tersebut diubah Hasil Kerajinan Desa Kasongan Banyak Diekspor ke Amerika. Kasus serupa sering dijumpai baik di koran lokal maupun koran nasional.

Kesalahan kosakata. Kesalahan ini sering dilakukan dengan alasan kesopanan (eufemisme) atau meminimalkan dampak buruk pemberitaan. Contoh: Penculikan Mahasiswa Oleh Oknum Kopasus itu Merupakan Pil Pahit bagi ABRI. Seharusnya kata Pil Pahit diganti kejahatan. Dalam konflik Dayak- Madura, jelas bahwa yang bertikai adalah Dayak dan Madura, tetapi wartawan tidak menunjuk kedua etnis secara eksplisit. Bahkan di era rezim Soeharto banyak sekali kosakata yang diekspose merupakan kosakata yang menekan seperti GPK, subversif, aktor intelektual, ekstrim kiri, ekstrim kanan, golongan frustrasi, golongan anti pembangunan, dll. Bahkan di era kebebasan pers seperti sekarang ini, kecenderungan pemakaian kosakata yang bias makna semakin banyak.

Kesalahan ejaan. Kesalahan ini hampir setiap kali dijumpai dalam surat kabar. Koran Tempo yang terbit 2 April 2001yang lalu tidak luput dari berbagai kesalahan ejaan. Kesalahan ejaan juga terjadi dalam penulisan kata, seperti: Jumat ditulis Jum'at, khawatir ditulis hawatir, jadwal ditulis jadual, sinkron ditulis singkron, dan lain-lain.

Kesalahan pemenggalan. Terkesan setiap ganti garis pada setiap kolom kelihatan asal penggal saja. Kesalahan ini disebabkan pemenggalan bahasa Indonesia masih menggunakan program komputer berbahasa Inggris. Hal ini sudah bisa diantisipasi dengan program pemenggalan bahasa Indonesia.

Untuk menghindari beberapa kesalahan seperti diuraikan di atas adalah melakukan kegiatan penyuntingan baik menyangkut pemakaian kalimat, pilihan kata, dan ejaan. Selain itu, pemakai bahasa jurnalistik yang baik tercermin dari kesanggupannya menulis paragraf yang baik. Syarat untuk menulis paragraf yang baik tentu memerlukan persyaratan menulis kalimat yang baik pula. Paragraf yang berhasil tidak hanya lengkap pengembangannya tetapi juga menunjukkan kesatuan dalam isinya. Paragraf menjadi rusak karena penyisipan-penyisipan yang tidak bertemali dan pemasukan kalimat topik kedua atau gagasan pokok lain ke dalamnya.

Oleh karena itu seorang penulis seyogyanya memperhatikan pertautan dengan (a) memperhatikan kata ganti; (b) gagasan yang sejajar dituangkan dalam kalimat sejajar; manakala sudut pandang terhadap isi kalimat tetap sama, maka penempatan fokus dapat dicapai dengan pengubahan urutan kata yang lazim dalam kalimat, pemakaian bentuk aktif atau pasif, atau mengulang fungsi khusus. Sedangkan variasi dapat diperoleh dengan (1) pemakaian kalimat yang berbeda menurut 
struktur gramatikalnya; (2) memakai kalimat yang panjangnya berbeda-beda, dan (3) pemakaian urutan unsur kalimat seperti subjek, predikat, objek, dan keterangan dengan selang-seling. Jurnalistik "gaya Tempo" menggunakan kalimat-kalimat yang pendek dan pemakaian kata imajinatif. Gaya ini banyak dipakai oleh berbagai wartawan yang pernah bersentuhan dengan majalah Tempo.

Agar penulis mampu memilih kosakata yang tepat mereka dapat memperkaya kosakata dengan latihan penambahan kosakata dengan teknik sinonimi, dan antonimi. Dalam teknik sinonimi penulis dapat mensejajarkan kelas kata yang sama yang nuansa maknanya sama atau berbeda. Dalam teknik antonimi penulis bisa mendaftar kata-kata dan lawan katanya. Dengan cara ini penulis bisa memilih kosakata yang memiliki rasa dan bermakna bagi pembaca. Jika dianalogikan dengan makanan, semua makanan memiliki fungsi sama, tetapi setiap orang memiliki selera makan yang berbeda. Tugas jurnalis adalah melayani selera pembaca dengan jurnalistik yang enak dibaca dan perlu. (Slogan Tempo).

Goenawan Mohamad pada 1974 telah melakukan “revolusi putih” (Istilah Daniel Dhakidae) yaitu melakukan kegiatan pemangkasan sekaligus pemadatan makna dan substansi suatu berita. Beritaberita yang sebelumnya cenderung bombastis bernada heroik--karena pengaruh revolusi-dipangkas habis menjadi jurnalisme sastra yang enak dibaca. Jurnalisme semacam ini setidaknya menjadi acuan atau model koran atau majalah yang redakturnya pernah mempraktikkan model jurnalisme ini. Banyak orang fanatik membaca koran atau majalah karena gaya jurnalistiknya, spesialisasinya, dan spesifikasinya. Ada koran yang secara khusus menjual rubrik opini, ada pula koran yang mengkhususkan diri dalam peliputan berita. Ada pula koran yang secara khusus mengkhususkan pada bisnis dan iklan. Jika dicermati, sesungguhnya, tidak ada koran yang betul-betul berbeda, karena biasanya mereka berburu berita pada sumber yang sama. Jurnalis yang bagus, tentu akan menyiasati selera dan pasar pembacanya.

Dalam hubungannya dengan prinsip penyuntingan bahasa jurnalistik terdapat beberapa prinsip yang dilakukan (1) balancing, menyangkut lengkap-tidaknya batang tubuh dan data tulisan, (2) visi tulisan seorang penulis yang mereferensi pada penguasaan atas data-data aktual; (3) logika cerita yang mereferensi pada kecocokan; (4) akurasi data; (5) kelengkapan data, setidaknya prinsip 5W 1H; dan (6) panjang pendeknya tulisan karena keterbatasan halaman (Suroso, 2001).

\section{PENUTUP}

Bahasa jurnalistik adalah suatu jenis bahasa yang digunakan oleh media masa dan sangat berbeda karakteristiknya dengan bahasa sastra, bahasa ilmu atau bahasa baku pada umumnya. Dalam hahasa jurnalistik wartawan harus menulis sesuai fakta dan tidak boleh beropini, namun tulisan tersebut harus mengandung makna informatif, persuasif, dan yang bisa dipahami secara umum, singkat, jelas dan tidak bertele-tele. Oleh karena itu, dapat disimpulkan bahwa bahasa jurnalistik adalah bahasa komunikasi masa yang bersifat singkat, padat, sederhana, lugas, menarik dan jelas. Artinya karakteristik bahasa jurnalistik meliputi kajian tentang sifat bahasa jurnalistik yang singkat dan padat berkaitan dengan prinsip ekonomi, menggunakan teks yang singkat tanpa merusak dan mereduksi pesan.. Sifat sederhana dan jelas berkaitan dengan konsumsi semua lapisan masyarakat dari berbagai tingkat pendidikan dan sosial ekonomi. Sifat sederhana juga berkaitan dengan tata bahasa dengan prinsip prosesibilitas, mudah dipahami pembaca. Sifat lugas berkaitan dengan kata yang bermakna sebenarnya. Yang tidak menimbulkan ketaksaan. Kalimat yang sederhana dan kata yang lugas berkaitan dengan kemampuan menimbulkan kejelasan informasi (pembaca tidak mengulangulang membacanya) dengan prinsip kejelasan yaitu menghindari ambiguitas. Sifat menarik berhubungan dengan gaya pemaparan yang terkesan. Mengalir dengan terarah, tidak terputus-putus; ini berkaitan dengan pembangunan penalaran: bagaimana sesuatu di paparkan; mulai dari mana dan 
berakhir dimana; semuanya harus menunjukan satu kesatuan informasi. Bahasa yang lancar akan menyebabkan tulisan menarik dengan prinsip ekspresivitas, teks dikonstruksi berdasarkan aspek-aspek pesan. Selain itu disimpulkan juga bahwa kebanyakan pemberitaan yang dimuat di media cetak di Indonesia dalam implementasinya belum memenuhi unsur-unsur yang menjadi karakteristik bahasa jurnalistik tersebut.

\section{DAFTAR PUSTAKA}

Anwar, R. (1991). Bahasa jurnalistik dan komposisi. Jakarta: Pradnya Paramita.

Badudu, J. S. (1988). Cakrawala bahasa Indonesia. Jakarta: Gramedia.

Halliday, M. A. K. (1972). Language Function and Language Structure. In J. Lions (Ed.), New Horizon of Linguistics. London: Penguin Book.

Leech, G. (1993). Prinsip-prinsip pragmatik. (D. D. Oka, terj). Jakarta: Penerbit Universitas Indonesia.

Lukas, L. (2006). Membangun kapasitas media. Jakarta: Sekretariat Dewan Pers.

McGoldrick, A., \& Lynch, J. (2000). Jurnalisme perdamaian bagaimana melakukannya? Seri Workshop LSPP, November 2000, Sydney.

Reah, D. (2000). The language of newspaper. New York: Roudledge.

Sudaryanto. (1995). Bahasa jurnalistik dan pengajaran Bahasa Indonesia. Semarang: Citra Almamater.

Suroso. (2001). Bahasa jurnalistik sebagai materi pengajaran BIPA tingkat lanjut. Bali: Presentasi pada KIPBIPA IV. 